\title{
RETHINKING THE CARBONATE CARBON ISOTOPE OF EDIACARAN DOUSANTUO FORMATION OF YICHANG IN SOUTH CHINA
}

\author{
Guan Chengguo, Wang Wei, Zhou Chuanming
}

State Key Laboratory of Paleobiology and Stratigraphy, Nanjing Institute of Geology and Palaeontology and Center for Excellence in Life and Palaeoenvironment, Chinese Academy of Sciences, Nanjing 210008, China

Numerous $\delta^{13} \mathrm{C}_{\text {carb }}$ studies of the Doushantuo Formation in South China have been carried out and widely used to explore the Ediacaran carbon cycling. Almost all previous studies were based on bulk rock samples. However, petrographic observations indicate that in the Doushantuo carbonates, calcite cements carrying carbon isotopic signatures of pore water are very common. To eliminate this diagenetic effect on the primary carbon isotopic feature, a sequential dissolution method was adopted in the present study. Carbonate samples, which were prepared for carbon isotope analysis, were first reacted with $30 \%$ phosphoric acid for $2 \mathrm{~h}$ to dissolve calcite. Measurements of reference samples show that this method works well in removing calcite from bulk sample, and can be used to study samples containing dolomite grains and calcite cements.

Three pronounced $\delta^{13} \mathrm{C}_{\text {carb }}$ negative excursions have been reported respectively in the cap dolostone unit (EN1), upper part of member II (EN2), and upper part of member III (EN3) of the Doushantuo Formation in the Yangtze Gorges area of South China. Our results indicate that there is no significant difference between $\delta^{13} \mathrm{C}_{\text {dolo }}$ and $\delta^{13} \mathrm{C}_{\text {bulk }}$ values for cap dolostone samples, but $\delta^{13} \mathrm{C}_{\text {dolo }}$ values increase sharply to positive values and remain relatively constant in the lower part of member II, which is in contrast to the highly fluctuating $\delta^{13} \mathrm{Cbulk}$ values reported in previous studies. For $\mathrm{EN} 2, \delta^{13} \mathrm{C}$ dolo values are significantly higher than and close to $\delta^{13} \mathrm{C}_{\text {bulk }}$ values at the lower and upper parts, respectively, indicating that EN2 is stratigraphically much shorter than previously reported. As to $\mathrm{EN} 3, \delta^{13} \mathrm{C}_{\text {dolo }}$ values are very close to $\delta^{13} \mathrm{C}_{\text {bulk}}$, suggesting minimum diagenetic influence. The remarkable differences between $\delta^{13} \mathrm{C}_{\text {dolo }}$ and $\delta^{13} \mathrm{C}$ bulk values for carbonate samples from the lower and upper parts of member II suggest that the addition of diagenetic cements may have great effect on $\delta^{13} \mathrm{C}$ values of carbonate rock samples, hindering our understanding of the primary carbon isotopic composition of seawater and carbon cycling in the Earth history. 